\title{
Los fundamentos de la responsabilidad civil en el consentimiento informado
}

Gustavo E. Montero Ordinola

Abogado por la Universidad San Martín de Porres. Máster en Derecho Civil y Comercial por la Universidad San Martín de Porres.

Profesor de la Facultad de Derecho de la Universidad de Lima y de la

Universidad San Martín de Porres.

SUMARI0:

I. Introducción.

II. La Práctica Médica.

1. En la Antigüedad.

2. En Grecia.

3. En el Medievo y la Edad Moderna.

III. El Paternalismo.

IV. La Reivindicación de los Derechos del Paciente.

V. Conclusiones. 


\section{RESUMEN:}

El paternalismo justificó durante siglos la intromisión del médico en la voluntad del enfermo. La concepción del hombre racional y moral aunado a los avances científicos en el siglo XX dio pie a los derechos del paciente y a la bioética, uno de cuyos pilares es el consentimiento informado. Se trata de determinar los fundamentos de la responsabilidad civil por su infracción, lo que justifica una revisión del sustento histórico que desembocó en la autodeterminación del paciente.

Palabras Clave: Derecho Civil, Responsabilidad Civil, Consentimiento Informado.

\section{ABSTRACT:}

Paternalism justified for centuries the meddling of the doctor in the patient's will. The conception of the rational and moral man, alongside the scientific advances of the 20th century gave rise to the rights of the patient and bioethics, one of the pillars of which being the informed consent. The purpose is to determine the grounds of civil liability for its infringement, which justifies a review of the historical support that led to the self-determination of the patient.

Keywords: Civil Law, Civil Liability, Informed Consent.

\section{INTRODUCCIÓN}

Es necesario que, previo al consentimiento del paciente, el facultativo le provea toda la información relevante al acto médico ${ }^{1}$ para que tome una decisión competente, informada y voluntaria. Es conveniente adoptar una tesis sobre los cánones del daño resarcible derivado del incumplimiento de este deber, aunque el objeto del estudio se centra en la razón que fundamenta esta responsabilidad. Como se desprende de la doctrina y de fallos dictados por tribunales extranjeros, no hay unanimidad en torno a los factores concurrentes para la procedencia de la indemnización. Se arguyen $^{2}$ factores como el traslado del riesgo hacia el médico que le niega a su paciente esta información, las posibilidades que habría tenido el paciente de no someterse al acto si hubiera contado con la información, la pérdida de oportunidad que el daño no hubiera sucedido si cabía la negativa del paciente con la información proporcionada, o la indemnización por el daño en sí.
Una dificultad que explica la variedad de hipótesis estriba en descubrir el nexo causal entre la infracción del deber del médico y el daño causado al paciente. En una suerte de síntesis se mencionan los siguientes factores recogidos en una sentencia española: que se produzca un daño físico cierto y probado en el paciente, que sea consecuencia de la materialización en la intervención médica de un riesgo típico o inherente a ella, que de él no se hubiera informado o no se le hubiere suministrado los datos convenientes al paciente y, finalmente, que el daño no sea atribuible a la negligente actuación del médico ${ }^{3}$. Aún con estas líneas directrices, la diversidad de pareceres dista de considerar cerrada la discusión.

Para dirimirla se debe apelar al dato histórico y con ello opinamos que debe serle inherente el daño moral al vulnerarse derechos fundamentales del paciente, sin que obviemos la diferencia entre la responsabilidad por el servicio negligente del médico y la derivada de la vulneración del

1. La Ley del Trabajo Médico —Decreto Legislativo 599-, su reglamento y el Código de Ética y Deontología del Colegio Médico del Perú consideran, en síntesis, que el acto médico condensa el diagnóstico, la terapéutica y el pronóstico.

2. ASUA, Clara. "Infracción de deberes de información y obligación de indemnizar en el ámbito sanitario". En: Revista CESCO de Derecho de Consumo № 8. España: 2013.

Asimismo, GIRALDO, Luis. "Los perjuicios derivados del incumplimiento del deber de solicitar el consentimiento informado al paciente" En: Investigaciones Andina Vol. XV No 26. Colombia: 2013, pp. 700-715.

3. STSJ NAVARRA 22/2001 el 27 de Octubre del 2001. 
consentimiento informado. La primera, frecuente en los tribunales, se debe a las deficiencias de los servicios sanitarios y se mide con criterios subjetivos; la segunda puede resultar no solo de la materialización de riesgos no informados sino, sobre todo, de la vulneración de la autonomía, de la autodeterminación y de la dignidad humana, aún sin manifestarse en un daño físico.

Nos centraremos en los principales rasgos históricos de la relación médico-paciente desde la antigüedad hasta la ruptura del paternalismo jurídico en el siglo anterior, y en la afirmación de principios como la autonomía y la dignidad humana, cimentando la autodeterminación del paciente y la responsabilidad por el quebrantamiento de un derecho fundamental de la persona. Recreamos la práctica médica en Grecia hasta el cambio con fallos de Tribunales Norteamericanos a principios del siglo XX y el establecimiento de un Código Ético en reacción a los horrores que se juzgaron en Nüremberg por la experimentación con prisioneros. Conjugando la ética y la vida, se da paso a la Declaración Universal de los Derechos Humanos hasta que se realzase la capacidad decisoria del paciente con la consagración de la Bioética en los años 70. Esta secuela marca el inicio del consentimiento informado y los problemas de la responsabilidad en un movimiento jurisprudencial que, por factores no analizados, no ha tenido un desenvolvimiento adecuado en nuestra realidad.

\section{LA PRÁCTICA MÉDICA}

\section{En la Antigüedad.}

La práctica médica en la antigüedad tenía el signo de la beneficencia paternalista. El enfermo espera- ba pasivamente las determinaciones del chamán como remoto predecesor del médico, con prácticas, ritos y ceremonias en la creencia de un origen mágico y sobrenatural de las enfermedades.

Las primeras regulaciones de la ética médica ${ }^{4}$ se originan alrededor del siglo VIII a.C. en Mesopotamia, cuando reinaba Hammurabi, al dictarse premisas sobre la moral, la medicina y un exigente listado de las responsabilidades del médico frente al enfermo. La medicina y los tratamientos se apoyaban en experiencias "mágico-religiosas" que no distinguían entre la medicina, la magia o la religión politeísta. La naturaleza resultaba inexplicable y se sobreponía al hombre en un mundo hostil y desconocido. Entre lo adversa de la naturaleza y la aceptación de una multiplicidad de dioses que se retroalimentaba con la fuerza de lo ignoto, la única explicación para todo, incluyendo la enfermedad, residía entre lo fantasioso y lo religioso. La incipiente legislación médica recogida en el Código de Hammurabi constituía una colección de sentencias, leyes y costumbres de la época. Aún con fecha imprecisa ${ }^{5}$, su texto evidenciaba la tendencia punitiva de una estructura dividida en patricios, plebeyos y esclavos.

La cultura hebrea trajo un cambio importante: la creencia en un solo Dios, dejando atrás los tótems y el politeísmo imperante en la prehistoria. A partir de ella hay un solo Dios, único, verdadero y justo. Para la medicina esto acarreó un cambio en el origen de la enfermedad ya que, a diferencia de los males propiciados por la naturaleza inhóspita o por los enemigos del propio hombre, es un castigo de Dios que todo lo puede y ordena como efecto del pecado. Ángel Rodríguez $z^{6}$ remarca que, para los hebreos, era Dios quien decidía los favores o

4. LUGONES, Miguel; PICHS, Luis y GARCÍA, Marlen. "Consentimiento informado". En: Revista Cubana de Medicina General Integral. 2005. Vol. XXI. N 5-6

5. GOMEZ-ULLATE, Susana. "Derechos Humanos, Biótica y Derechos de los Pacientes". Tesis doctoral dirigida por Rafael Junquera y Jaime Zabala. UNED, 2015. Se estima que este texto jurídico es de los siglos XX al XVIII a.C., proclamado por el Sexto Rey de la Sexta Dinastía I de Babilonia, cuyo nombre lleva el Código. Los preceptos diferenciaban las penas según la clase social a la que perteneciera el enfermo.

6. RODRIGUEZ, Angel. "La Medicina y en los Textos Sagrados. Asociación Española de Médicos Escritores y la Sociedad Española de la Historia de la Medicina", Planeta Médico. Disponible en: < medicina/planeta medico/curiosidades/biblia.php> 
perjuicios de la salud, condicionando la actitud que se mantiene en el mundo cristiano dada la voluntad divina omnipresente y hasta milagrosa. En el Antiguo Testamento se encuentran numerosos pasajes que dan cuenta de un Dios protector del alma y del cuerpo ${ }^{7}$. El autor hace hincapié en la correlación de pecado y enfermedad. Este presupuesto perduró varios siglos y fue visto como una confirmación del paternalismo y frenó al desarrollo de la medicina en el medioevo pues, si Dios todo lo crea y todo lo puede, la curación corporal dependerá en última instancia de su voluntad al estar nuestro cuerpo en manos de la divinidad.

\section{En Grecia.}

Se señala la época de la Grecia clásica, entre los siglos VI y V a.C., como la cuna de la medicina, al fundarla en un sistema y un método y dotarla de un marco científico, filosófico y ético cuya égida se prolonga hasta nuestros días. El personaje central fue Hipócrates de $\operatorname{Cos}^{8}$, nacido en la isla de Cos, en 460 a.C. Durante su juventud viajó por toda Grecia y estudió Filosofía en Atenas, volviendo adulto a la isla en la que nació para dedicarse a practicar y enseñar los conocimientos en medicina que había aprendido en sus viajes $^{9}$. Entre sus contribuciones más importantes se cuenta la "Propedéutica de la Clínica" por la inspección del enfermo desde la cabecera de su cama y la explicación de las enfermedades internas con el trastorno de los fluidos corporales compuestos por los 4 humores en el organismo: sangre, flema, bilis amarilla y bilis negra, dejando para la posteridad sus célebres aforismos ${ }^{10}$.

Como lo anota Gómez-Ullate ${ }^{11}$, la contribución más importante es "la desvinculación entre la causación mágica y la realidad natural del mundo" ya que, a pesar del origen mitológico de la medicina, se colocan los cimientos de una ciencia diferenciada de las explicaciones mágicas y religiosas de los siglos anteriores. Los griegos aportaron una cultura científica y racional fundamentada en la naturaleza o physis. Se reconoció el kosmos, religioso y mítico, del que derivaron los primeros intentos de filosofar e instaurar el estudio acerca de la naturaleza, de la que se desprenden propiedades y virtudes propia de cada cosa. La naturaleza no cambia, es estable; surgiendo ideas como la génesis y el desarrollo aplicables, entre otros campos, en la medicina. Además, el hombre tiene una técnica para coadyuvar en la ejecución de la naturaleza, denominada tekhne. Por último, surge una physiologia humana - physis - naturaleza y logia - ciencia- que es la ciencia médica para estudiar al hombre, la enfermedad y la curación.

Hipócrates inspiró — se dice que no escribió del todo- ${ }^{12}$ el Corpus Hippocraticum y el Juramento Hipocrático que perduran hasta nuestros días, de los que son relevantes el aspecto deontológico que normaba la relación entre el médico, el enfermo y su entorno. Su máxima era curar, aliviar, consolar y no hacer daño, que se manifestaba en lo que fuere más beneficioso al paciente al

7. Éxodo 15:26: "Si deberás escuchar la voz del Señor, tu Dios, y haces lo que es recto a sus ojos, dando oídos a sus mandatos y guardando todos sus preceptos, no traeré sobre ti ninguna de las plagas que envié sobre los egipcios; porque Yo soy el Señor, el que sana".

8. PATIÑO, Jose. “Legado quirúrgico de Hipócrates”. En: Revista Colombiana de Cirugía. 2008. Vol. XXIII, № 4, pp. 191196. Es interesante anotar el origen mitológico de curar representado en Grecia por Apolo y Artemisa.

9. ANTILLÓN, Juan Jaramillo. "Conversaciones con Hipócrates de Cos padre de la medicina". En: Revista Médica de la Universidad de Costa Rica 3.1. 2009.

10. Loc. Cit. Entre ellos tenemos: "El médico no puede obtener el éxito en la curación de un enfermo si este no le ayuda, si no cuenta con buenos asistentes y si las circunstancias exteriores no le favorecen. Esto es básico en cirugía" o "Son preferibles las comidas que agraden al enfermo, aunque no sean buenas, a las que le desagraden, aunque sean mejores, ya que no suele comerlas".

11. GOMEZ-ULLATE, Susana. Op Cit. p. 64

12. Op. Cit.p. 5. 
que se le daba lo mejor por encima de cualquier interés propio o ajeno.

A pesar del notable avance en el pensamiento racional que dio pie a la técnica médica y al avance ético en el comportamiento del médico, subsistió el paternalismo médico justificado ${ }^{13}$ por la idea del orden natural y la justicia social en una sociedad que debe guardar equilibrio y armonía en virtud de la justicia. Como un microcosmos del Estado, se encontraba la familia patriarcal en cuyo seno era el padre quien decidía y gobernaba. Trasladado este modelo a la relación particular entre el médico y su paciente, el primero es el patriarca que domina y aquel le debe obediencia porque el tratamiento lo tiene a él como único beneficiario.

Este principio de beneficencia justificaba la actuación del médico y consagraba la relación desigual: ante su sabiduría y técnica, nada puede opinar el enfermo. El equilibrio entre el bien y el orden se rompía con la enfermedad y su restitución con la curación se inscribía en el plano natural y el filosófico por obra del médico colaborador en la reconformación del kosmos. Esto explicaba la posición privilegiada del médico cuya técnica estaba al servicio del enfermo que era sometido por los principios de beneficencia, no maleficencia y confiabilidad.

En suma, Grecia trajo al mundo la técnica, la ciencia, la ética médica y un conjunto de obras que dieron fundamento a la medicina moderna, pero el paciente debía someterse a las decisiones del médico que obraba con el propósito de sanarlo y no causarle daño.

\section{En el Medievo y la Edad Moderna.}

La herencia de la medicina hipocrática perduró hasta aproximadamente el siglo XV. Si en Grecia el médico era el conocedor del arte y la técnica, era impensable que el enfermo tuviera algo que decir. Solo obedecía lo que el primero dispusiera para restablecer el orden natural alterado por la enfermedad.

El Medievo fue dominado inicialmente por el cristianismo, que innovó pautas sobre la enfermedad. Laín ${ }^{14}$ encuentra en referencias bíblicas una nueva actitud de la medicina: al enfermo se le cuidaba en orden a un mandamiento, por amor al prójimo y debido a la prédica de asistencia al hermano. La filantropía y la asistencia al prójimo y por ende al enfermo ${ }^{15}$, se manifestó en servicios sociales hacia los enfermos y viudas, creación de hospitales ${ }^{16}$, la incorporación del consuelo y la compasión y la asistencia gratuita hacia el pobre.

Es en el siglo $\mathrm{XI}^{17}$ que se apreció el mayor avance de la medicina con la maduración intelectual y política favorecida por el surgimiento de las ciudades y la "secularización del conocimiento". En el siglo XIII, nacen las primeras Universidades y se profesionaliza la medicina, que pasa de estar en manos de los clérigos a los hombres

13. MICHELLI-SERRA, Alfredo." Entorno a la ética profesional del médico". En: Gaceta Médica de México. 2004. Vol. CXL, No 1. pp. 89-92.

14. LAÍN ENTRALGO, Pedro. "Historia de la Medicina". Barcelona. Salvat, 1978, vol. CCCLXIII, p. 140. En la siguiente cita ve la desvinculación de la enfermedad con el pecado y paradójicamente los cristianos parecen no haber aprendido esta lección: «Maestro, ¿quién ha pecado para que este hombre haya nacido ciego, él o sus padres? -Niél ni sus padres han pecado; sino que esto ha sucedido para que las obras de Dios sean en él manifiestas» (Jo. IX, 1-3). Luego encuentra el fundamento de la caridad con el doliente en quien se encarna Cristo: "«Estuve desnudo y me vestisteis, enfermo y me visitasteis, en la cárcel y fuisteis a verme. Entonces los justos le replicarán: Señor... ¿cuándo estuviste enfermo o en la cárcel y fuimos a verte? Y el rey —Cristo en su trono-les responderá: Os lo aseguro. Cada vez que lo hicisteis con uno de mis hermanos más humildes, conmigo lo hicisteis» Mateo XXV, 35-40.

15. Op. cit, p. 141

16. LAÍN ENTRALGO, Pedro, Op. cit., p. 141, se dice que el primero fue creado por el Obispo Basilio el Mago, doctor de la Iglesia, en Cesárea de Capadocia —Asia Menor_, al alrededor del siglo IV d.C.

17. GOMEZ-ULLOTE, Susana. Op. Cit. p. 122. 
instruidos. Se pasa de la relación con el paciente, explicada por la autoridad moral del médico, a una relación burocrática ${ }^{18}$.

A fines de la Edad Media y comienzos de la Edad Moderna, continuó el avance del conocimiento desligado de la religión, se abandonó el asistencialismo cristiano por un pensamiento científico. Surgió una verdadera profesión médica sin abandonarse la idea acendrada de omitir información al enfermo. No se confiaba en el médico por representar la voluntad de Dios, sino por tener autoridad en la profesionalización de la carrera, con lo que habría razones para desdeñar la opinión del enfermo. Esta paternidad legal justificó la sumisión del paciente. Además, los médicos aumentaron su prestigio al monopolizar el ejercicio de la profesión ${ }^{19}$, abriéndose las primeras Facultades de Medicina en que se otorgaban títulos superados los rigurosos controles y una dilatada práctica médica.

Este apogeo de la ciencia justificó el dominio de la naturaleza, debido a su saber técnico, en tanto que el paciente le debía fe ciega en la idea que la ciencia y el saber científico lo podía todo. El ser humano se convirtió en objeto de la ciencia y fue tratado más como un elemento físico y material cognoscible.

\section{EL PATERNALISMO}

La relación particular en estudio se asentó desde la prehistoria en el paternalismo estudiado como corriente de pensamiento desde mediados del siglo XX.

Surge de la extrapolación ${ }^{20}$ del modelo paterno-filial a relaciones como el Estado y los ciudadanos o el médico y su paciente. En la base está el bienestar individual amenazado por el propio individuo, lo que justifica una intromisión en la voluntad y las decisiones ajenas. Se habla de una "intervención coactiva en el comportamiento de una persona a fin de evitar que se dañe así mis$m a^{\prime \prime 21}$. Ejemplos de esta corriente son medidas como la prohibición de la venta de drogas, el uso de cinturones en automóviles, los aportes para la jubilación o las prohibiciones de venta de medicamentos sin receta, de bañarse en playas peligrosas o de participar en juegos de azar ${ }^{22}$. Agregamos nosotros, la capacidad decisoria del médico sobre el paciente, sin importar su opinión ni su consentimiento.

Alemany ${ }^{23}$ señala que los elementos de una relación paternalista son los sujetos, el modo y la finalidad; y agrega que este último caracteriza al verdadero paternalismo por su finalidad benevolente y la acción positiva de un sujeto dominante en otro. El sujeto paternalista beneficia a otro evitándole daños físicos, psíquicos o económicos aún contra las preferencias que tuviere el beneficiado en el momento de la intervención. Esto se explica en la medida que el protector sepa lo que conviene al otro sujeto, al ser este capaz de tener una preferencia contraria a lo que dicta la decisión paternalista ${ }^{24}$. En con-

18. Ibíd., p. 130.

19. Ibíd., p. 141. La autora señala que mientras algunas profesiones para constituirse como tales necesitan una constitución "negativamente privilegiada" incrementando su poder con técnicas de apertura, otra, como la médica de esa época, debían ser "positivamente privilegiadas", es decir, disminuir su tamaño para impedir la entrada de los no privilegiados. Con ello, además, se descartaban a los empíricos, hechiceros y demás personajes que no podrían acceder a un quehacer educativo cerrado.

20. ALEMANY, Macario. “El concepto y justificación de paternalismo”. 2005. Doxa N² 28. p. 266.

21. GARZON, Ernesto. “Es éticamente justificable el paternalismo jurídico?” Doxa Nº 5, año 1988, p. 155.

22. Son medidas dignas de aplauso en una comunidad que puede no ser consciente de esta corriente.

23. ALEMANY, Macario. Las estrategias de la benevolencia: sobre las relaciones entre paternalismo y la bioética". Doxa $\mathrm{N}^{\circ}$ 26, 2003, p. 771.

24. Íbid., p. 774. 
secuencia, la acción paternalista consigue que una persona haga lo que de otra manera no habría hecho. En otro trabajo ${ }^{25}$, el mismo autor discrepa de quienes diferencian el paternalismo de una conducta estrictamente benevolente al haber autores que lo limitan a una mera coacción, interferencia con la libertad, falta de respeto, violación de la autonomía, engaño u ocultación de información, entre otros aspectos negativos que colisionan con la benevolencia.

Para Alemany, la confusión puede deberse a que el paternalismo requiere un ejercicio de poder para obtener intencionalmente un comportamiento o influir en él, aunque ya lo anotamos, se trata de una conducta benevolente. La definición del paternalismo sería la siguiente ${ }^{26}$ : “EI agente $A$ ejerce paternalismo sobre $B$, si y solo si: 1) A ejerce poder sobre $B, 2$ ) con la finalidad de evitar que B lleve a cabo acciones u omisiones que le dañan asimismo y/o le suponen un incremento del riesgo de daño - siendo estos daños de tipo físico, psíquico o económico -."

Garzon $^{27}$ señala los argumentos que se hacen valer en contra de paternalismo jurídico y las razones que pueden justificarlo en ciertos casos. Entre las razones contrarias, menciona el argumento utilitarista, el del respeto a la autonomía de la persona y el de la violación del principio de igualdad. El primero lo fundamenta en las tesis de John Stuart Mill, para quien no hay mejor juez que uno mismo para saber qué le daña o no daña de acuerdo a sus propios intereses ${ }^{28}$. El segundo argumento del respeto a la autonomía se materializa en la capacidad de elección de conformidad con una ley moral; y el tercero, tiene que ver con la violación del principio de igualdad roto por la subordinación en una determinada relación social ${ }^{29}$.

En todo caso Valdez también justifica algunos tipos de paternalismo ${ }^{30}$ con el argumento del consentimiento expreso o hipotético de quien es tratado paternalistamente ${ }^{31}$, el que sólo puede ser otorgado a futuro. Schlack ${ }^{32}$ aborda este tema en el desarrollo de la Jurisprudencia del Tribunal Supremo Federal de Alemania por el incumplimiento de los deberes de información en el ámbito de las intervenciones médicas curativas. La ley alemana declara inválido el consentimiento de la víctima si el médico falta a dicha regla que apareja la imposibilidad de obtener el consentimiento expreso de la víctima. Pero el médico no será punible si obtuvo el consentimiento, funcionando incluso el principio in dubio pro reo en su favor, al crearse la presunción que la víctima hubiera consentido la intervención en caso de haber sido informado suficientemente, salvo que se pruebe indubitablemente que aún con la información no hubiera prestado dicho consentimiento. Es una muestra concreta, aunque discutible, de la bondad del paternalismo justificado por el presunto consentimiento

25. ALEMANY, Macario. "El concepto y justificación de paternalismo". 2005. Doxa № 28. p. 268.

26. ĺbid, p. 273.

27. Íbid., p. 158.

28. GARZON, menciona como caso límite contrario a esta posición que el propio Mill advirtió, el del contrato de esclavitud cuando alguien lo suscribe renunciando a su libertad, por ejemplo, para recibir a cambio una suma de dinero que le permita salvar a sus hijos de la miseria y el hambre. Con ello considera que las premisas del utilitarismo son falsas si pretenden ser universalmente validas ya que se trata de una decisión moralmente inaceptable.

29. Un caso local lo sería en nuestro medio la Ley 30021 — conocida como "Ley de comida chatarra" — que restringe el consumo de ciertos productos entre niños y adolescentes en aras de una alimentación saludable.

30. ALEMANY, Macario. Op. Cit. p.164

31. Es el caso de los Contratos Ulises en las que el propio individuo se pone en manos de otro.

32. SCHLACK, Andres: "El consentimiento hipotético de la víctima en el derecho penal alemán." En: Revista de Derecho de la Universidad Católica del Norte (online). Vol. I. № 1. Chile: 2001 
del paciente a las actividades médicas de las que será destinatario en el futuro.

\section{LA REIVINDICACIÓN DE LOS DERECHOS DEL PACIENTE}

Fue necesario que convergieran dos elementos en el contexto social y político para provocar la crisis del paternalismo vigente durante varios siglos en la relación médica: el desarrollo de ideales de libertad e igualdad en los principios de autodeterminación y autonomía sobre la base de la dignidad humana, debido a un desarrollo de los derechos fundamentales a partir de Locke ${ }^{33}$ como precursor de los derechos civiles y políticos; así como de la idea de la autonomía a partir de Kant y Mill ${ }^{34}$, el primero con el individuo racional que actúa por principios morales universales, y el segundo, por la libertad individual propia de la modernidad. El otro factor fue el extraordinario avance científico que planteaba nuevos retos éticos desconocidos hasta la fecha.

Existe consenso en determinar que el consentimiento informado llegó a la práctica médica con pronunciamientos dictados en los tribunales norteamericanos a principios del siglo XX. El hito lo marca el caso Schloendorff vs Society of New York Hospitals en 1914 con el célebre pronunciamiento del Juez Cardozo en el sentido que:

"(...) todo ser humano de edad adulta y juicio sano tiene derecho a determinar lo que debe hacerse con su propio cuerpo; y un cirujano que realiza la intervención sin el consentimiento de su paciente comete una agresión por la que se le pueden reclamar daños".

Pero, es en el caso Salgo contra Leland Stanford $J r$. University Broard of Trustees, cuando se usa por primera vez la expresión consentimiento informado ${ }^{35} ; y$, en 1972 , se da un paso más en esta tendencia en el caso Berkey contra Anderson ${ }^{36}$.

Como anota López Calera ${ }^{37}$, hoy son evidentes la complejidad ética y jurídica en el personal sanitario y el desarrollo científico y técnico con retos de la ciencia biomédica cada vez mayores. A diferencia del siglo XIX, las posibilidades científicas de prolongar la vida de una persona nos sitúan frente a la pregunta de hasta dónde se debe sostener artificialmente la vida de esta persona. El paternalismo jurídico supone el control de la vida de las personas y el autor cree que en la práctica moderna no está descartado que se piense en esta tesis para salvaguardar el interés de los pacientes como común denominador de la medicina y de las políticas sanitarias. A pesar de ello, el autor entiende "que la medicina no puede venir impuesta al paciente" ${ }^{\prime 38}$ y que la autodeterminación del paciente es importante en la toma de decisiones pues, si lo que está en juego es la vida o la muerte de una persona, es importante que el paciente, en cuanto pueda, diga algo sobre su vida o muerte. Por eso no duda en afirmar que el principio fundamental para limitar el paternalismo es el "consentimiento informado" —informed consent- porque lo contrario sería la negación del derecho de autonomía.

33. GOMEZ-ULLOTE, Susana. Op. Cit. p. 178

34. CURBElO PEREZ, David. "Principio de Autonomía, Menores y Práctica Médica". Tesis doctoral dirigida por Rafael Pérez Junqueira. UNED 2013.

35. GOMEZ-ULLOTE, Susana. Op. Cit. p. 195. En la sentencia del caso Salgo el Juez señala que: "Los médicos tienen el deber de revelar todos los hechos que sean relevantes para forjar las bases de un consentimiento del paciente al tratamiento propuesto".

36. En la sentencia se adujo: "El derecho del paciente a la autodeterminación y por tanto a decidir si admite o no un procedimiento después de haber conocido y comprendido sus riesgos y alternativas. La información forma parte de los deberes profesionales de cuidado".

37. LÓPEZ CALERA, Nicolás. "La vida y la muerte ante la ética y el derecho: paternalismo médico y desarrollo científico". Doxa. N 15-16, pp. 715-729.

38. Ibíd., p. 719. 
Entre los fallos de los Tribunales norteamericanos, un hito decisivo para el nacimiento de la bioética lo constituyó el Código de Nüremberg en 1947 que contiene 10 puntos para regular la experimentación en los seres humanos, delineando los conceptos de información y consentimiento pertinazmente desconocidos en los campos de concentración nazis en lo que se sometieron a los prisioneros a "pruebas de supervivencia" con hambre, frío, infecciones inducidas, mutilaciones quirúrgicas, esterilizaciones y eugenesia ${ }^{39}$. Estos principios fueron confirmados en la Declaración de Helsinski de 1964, elaborada por la Asociación Médica Mundial que pasó a ser una norma internacional sobre ética en la investigación biomédica ${ }^{40}$.

En 1948 se dictó la Declaración Universal de los Derechos Humanos ${ }^{41}$ y en el año 2005 la UNESCO proclamó la Declaración Universal sobre Bioética y Derechos Humanos orientada a tratar las cuestiones éticas de la medicina, las ciencias de la vida y las tecnologías conexas aplicadas a los seres humanos, teniendo en cuenta sus dimensiones sociales, jurídicas y ambientales, con el objetivo de proporcionar un marco universal de principios, políticas $u$ otros instrumentos en el ámbito de la bioética y promover el respeto a la dignidad humana, a la protección de los derechos humanos, el respeto de la vida de los seres humanos y de las libertades fundamentales.

Un documento importante es el denominado "Informe Belmont"42 elaborado en el año 1979 por la Comisión Nacional para la Protección de los Sujetos Humanos de Investigación Biomédica y del comportamiento del Departamento de Salud, Educación y Bienestar de los EE.UU., cuyo título era "Principios y guías éticos para la protección de los sujetos humanos de investigación". Este informe parte del reconocimiento tanto de los beneficios de la investigación como de los problemas éticos y de su impacto en los experimentos biomédicos practicados en los seres humanos, especialmente durante la Segunda Guerra Mundial, que dieron lugar a los procesos de Nüremberg contra los crímenes de guerra. La declaración pretende distinguir entre investigación y práctica, y realza tres principios éticos básicos y las observaciones sobre su aplicación. Los tres principios éticos básicos son los siguientes: el respeto de las personas, la beneficencia y la justicia. Los tres elementos en miras a su validez son la información, la comprensión y la voluntariedad.

Se atribuye a Van Rensselaer Potter, en el año 1970, en los EEUU, la autoría del término Bioética, conjuntamente con André Hellegers ${ }^{43}$. Fernández, considera que entre el dilema de considerar a la bioética como disciplina filosófica o como práctica, se inclina por lo último, al ser una praxis permeable al conocimiento de la ciencia médica, a la escucha del ser humano, a criterios religiosos y espirituales y a los derechos ciudadanos en dirección a la ética concluyendo que la bioética en sentido amplio no es más que la ética en una situación concreta. Tomar Romero ${ }^{44}$ señala que el objeto de la

39. TEALDI, Juan Carlos. "Historia y significado de las normas éticas internacionales sobre investigaciones biomédicas". En: Keyeux G, Penchaszadeh V, Saada A (Coordinadores). Ética de la Investigación en seres humanos y políticas de salud pública. Bogotá: UNESCO-Universidad Nacional de Colombia, 2006, pp. 33-62.

40. Ibíd., p. 35.

41. En su Artículo primero se estatuye que: "Todos los seres humanos nacen libres en dignidad y derechos y, dotados como están de razón y conciencia, deben comportarse fraternalmente los unos con los otros".

42. Hemos considerado el texto en sus versiones de castellano e inglés en el Centro de Documentación de Bioética de la Universidad de Navarra o el del Observatorio de Bioética y Derecho de Barcelona. Cfr: <http://www.unav.es/ cdb/usotbelmont.html $>$ y <http://www.bioeticayderecho.ub.edu/archivos/norm/InformeBelmont.pdf $>$

43. FERNÁNDEZ AGIS, Domingo. "La Bioética: ¿disciplina filosófica o mera praxis?" En: Dilemata № 2: 2010, pp. 49-54

44. ROMERO, Francisca Tomar. "El lugar del hombre y la antropología en la bioética". En: Cuadernos de bioética, vol. XXIV, № 81. Madrid: 2013, pp. 179-188. 
bioética es la conducta humana en un marco a la vez concreto y amplio, como es la ciencia de la vida y de la salud y abarca problemas éticos en el personal sanitario, problemas morales en a investigación sobre el hombre, problemas sociales en las políticas sanitarias, problemas en la intervención en otros seres vivos y finalmente los atinentes a la biósfera.

Es con Tom Beauchamps y James Childress y su libro "Principios de la ética biomédica" publicado en 1979, que se construye un sistema teórico-práctico que aborda los problemas fundamentales de la ética y la medicina sustentado en 4 principios $^{45}$ :

\begin{abstract}
"Principio de No-Maleficencia: Debe evitarse realizar daño físico, psíquico o moral a las personas. Principio de Justicia: Debe procurarse un reparto equitativo de los beneficios y las cargas, facilitando un acceso no discriminatorio. Principio de Autonomía: Debe respetarse que las personas gestionen su propia vida y tomen decisiones respecto a su salud y su enfermedad. Principio de Beneficencia: Debe promocionarse el bienestar de las personas, procurando que realicen su propio proyecto de vida y felicidad en la medida de lo posible".
\end{abstract}

Simón ${ }^{46}$ piensa que el verdadero fundamento del consentimiento informado es la articulación adecuada de estos principios ya que en un primer plano coloca a la no-maleficencia y la justicia en el marco estructural de la relación clínica como una garantía de las organizaciones sanitarias para evitar riesgos y poner a disposición los procedimientos y técnicas más efectivas para la promoción de la salud y, en un segundo plano, coloca a la beneficencia y la autonomía, para regular las obligaciones que nacen de esta relación.
Curbelo ${ }^{47}$ se refiere a la autonomía en sentido ontológico - esferas de la realidad autónomasy ético - la ley moral es autónoma cuando tiene en si misma su fundamento y su razón propia de legalidad-, lo que aplicado al hombre supone tener capacidad para darse a sí mismo sus leyes y ser capaz de realizarlas. Hay así una autonomía moral, por la capacidad que tiene toda persona de proponerse fines y proyectarse al futuro; $y$ autonomía práctica, por la capacidad de elegir entre bienes o diferentes cursos de acción. Concluye que la bioética no se refiere a la autonomía en si sino al respeto por el principio de la autonomía, lo que presupone reconocer la capacidad de la persona para tomar decisiones en base a sus creencias y valores personales.

En última instancia se trata del derecho a la vida y a la dignidad humana en la base de los derechos del enfermo. Gómez Ullote afirma que ${ }^{48}$ :

"La dignidad es inherente al ser humano y este, por sí mismo y, por el mero hecho de serlo, es digno de respeto y de inviolabilidad. Se produce así una necesaria consecuencia: Entre la dignidad y el derecho a la vida existe una dependencia troncal y relacional y, ¿qué es el fundamento último de protección esencial de cualquier persona enferma si no el derecho a la vida de esta respetando en última instancia la dignidad de la misma?".

Ante este fundamento, la infracción al deber que tiene el sistema sanitario de obtener el consentimiento informado es una violación de principios fundamentales tan inherentes al ser humano, como el derecho a la vida, a la dignidad humana, a la autonomía y a la autodeterminación que se traducen en daño moral. Desde luego, hay problemas por dilucidar. López Calera ${ }^{49}$ apunta

45. SIMON, Pablo. "Diez mitos en torno al consentimiento informado". En: Anales Sis San Navarra, Vol. XXIX. Pamplona: 2006, pp. 29-40.

46. Ibíd., p. 33.

47. Ibíd., p. 13.

48. Ibíd., p. 175.

49. Ibíd., p. 720. 
a dos; uno referido a lo que él llama los "hechos", es decir que la diagnosis y los tratamientos conllevan aspectos científicos sobre los cuales es el médico el primero que debe pronunciarse, y otro a los objetivos, valores o finalidades que pueden derivarse de los hechos y sobre los cuales primero debe pronunciarse el enfermo. De la Maza ${ }^{50}$, apunta que la autodeterminación es uno de los intereses que se deben considerar, pero no el único, porque también debe atenderse a la viabilidad de la práctica médica que sería imposible si se exigiera al médico que suministre toda la información pertinente, además de la protección del paciente en casos de suma urgencia o de un riesgo escaso frente a un paciente singularmente temeroso. Por eso propone al consentimiento informado como un dispositivo de ponderación por el que el legislador debe asignar pesos específicos a los intereses en conflicto para decidir una controversia.

\section{CONCLUSIONES}

El paternalismo médico se fundó en razones propias de la cosmovisión de cada época, desde las explicaciones mágico-religiosas de la antigüedad, pasando en Grecia por la autoridad benevolente del médico, el asistencialismo cristiano del medievo hasta la autoridad científica del médico en el siglo XIX. En todas le fue negada al enfermo cualquier capacidad decisoria sobre su salud.

El fin ideológico de esta larga etapa se debió a movimientos políticos en la Europa de los siglos XVIII y XIX, cuyas proclamas más importantes fueron la igualdad y la libertad con un pensamiento liberal que proclamaría los derechos del paciente.

El juzgamiento de Nüremberg que puso al descubierto la degradación en los experimentos humanos y los impresionantes avances científicos del siglo XX, plantearon nuevos retos en la ética médica surgiendo la bioética con sus principios y fundamento en el consentimiento informado. La responsabilidad por su infracción se funda en la violación de un derecho fundamental y en el daño moral ocasionado por el desconocimiento de la autonomía y la dignidad humana.

50. DE LA MAZA GAZMURI, Iñigo. “Consentimiento Informado, Una Visión Panorámica”. En: lus et Praxis, Vol. XVI, № 2. Lima: 2010, pp. 89-120. 